\title{
'Their life in your hands': The experiences of prison-based psychologists conducting risk assessments with indeterminate sentenced prisoners in the United Kingdom
}

Jo Shingler*a, Stefanie J. Sonnenberg ${ }^{\mathrm{b}}$, and Adrian Needs ${ }^{\mathrm{c}}$

${ }^{a}$ Department of Psychology, University of Portsmouth, United Kingdom; ${ }^{b}$ Department of Psychology, University of Portsmouth, United Kingdom; ${ }^{c}$ Department of Psychology, University of Portsmouth, United Kingdom

*Corresponding author information: Jo Shingler, Department of Psychology, University of Portsmouth, King Henry Building, King Henry $1^{\text {st }}$ Street, Portsmouth PO1 2DY, UK, (joanne.shingler@port.ac.uk; up707929@myport.ac.uk) 
'Their life in your hands': The experiences of prison-based psychologists conducting risk assessments with indeterminate sentenced prisoners in the United

\section{Kingdom}

Assessing prisoners' risk of recidivism and making risk-management recommendations is central to the work of prison-based psychologists. Risk assessment is particularly crucial when it involves indeterminate sentenced prisoners: psychologists' recommendations have potentially significant consequences both for prisoners and the public. However, little is known about psychologists' experiences of conducting such high stakes risk assessments. This paper reports the results of an exploration of psychologists' experiences, via interviews and discussions with qualified, prison-based psychologists. Analysis using Grounded Theory methods identified one super-ordinate category of meaning, namely The Challenging Context of Risk Assessment, which comprised two subcategories: (1) pressure of limited resources and (2) pressure of the environment. An additional major category, Risk Assessment as a Weighty Task, comprised three sub-categories: psychologists described (1) a weight of responsibility relating to the magnitude and range of their responsibilities; (2) a weight of expectation from colleagues to provide solutions, and (3) the trainee dilemma associated with the need to balance development of trainee psychologists' competence in risk assessment with being held accountable for their work. Understanding qualified psychologists' experiences of undertaking risk assessments with indeterminate sentenced prisoners can facilitate improvements and build on areas of existing good practice. 
Keywords: risk assessment; prisons; indeterminate sentence;

psychologists.

Word count: 


\section{Introduction}

Risk assessment is central to the work of prison-based forensic psychologists (Bowers \& Friendship, 2017; Kebbell, 2016), to Parole Board decision making, and to indeterminate sentenced prisoners' (ISPs) futures. ${ }^{1}$ However, there is little empirical research into these groups' views and experiences of risk assessment. To address this gap, this paper reports the results of an exploration of psychologists' experiences of conducting risk assessments in prisons. A better understanding of this crucial area of work would help to identify tensions, stresses and potential sources of bias, reveal aspects of good practice and suggest ways forward.

\section{The task of risk assessment}

Psychologists working in prisons engage in numerous professional duties, including direct assessment and intervention work with prisoners, supervising the work of others (including Forensic Psychologists in Training), supporting, advising and training prison managers and operational staff and conducting research. Within this range of duties, working on psychological risk assessments for consideration by the Parole Board, as either the assessor or supervisor of the assessor, takes up a significant amount of psychologists' time and resources. The task of psychological risk assessment with ISPs is also a challenging one, involving a number of complex judgements. Psychologists must provide an opinion about a prisoner's likelihood of reoffending. They must also consider the nature and imminence of risk; aspects of the prisoner's psychological functioning underpinning his risk; factors that might increase risk or protect against it; the psychological, social or environmental interventions that might assist in reducing or managing risk; and the suitability of the prisoner for release or transfer to less secure

\footnotetext{
${ }^{1}$ In the United States the equivalent sentence is 'life sentence with the possibility of parole'.
} 
prison conditions (Vess, Ward \& Yates, 2017). The tasks involved in forming these judgements are equally challenging. They include encouraging prisoners' co-operation; gathering and analysing collateral information (from prison files and consultations with colleagues); using specific psychological assessment tools or tests; interviewing the prisoner; reporting the outcomes in writing; and giving oral evidence to a panel of the Parole Board, the decision making body for ISPs in England and Wales.

Providing evidence to inform Parole Board decisions is particularly important. The Parole Board can direct the release of an ISP only when it is 'satisfied that it is no longer necessary for him/her to be detained in order to protect the public from serious harm' (Parole Board, 2018, para. 3). Panels of the Parole Board increasingly rely on psychological opinion to make decisions about risk and progress for ISPs (Bowers \& Friendship, 2017; Shingler, 2017; Shingler \& Needs, 2018a) and there appears to be a view amongst prisoners that psychologists' opinions carry the most weight in parole decision making (Crewe, 2012; Sparks, 1998). Thus, psychological risk assessment plays a significant role in the work of the Parole Board and the lives of ISPs. The consequences of errors in risk assessment are notable - false positives resulting in lengthy, expensive and unnecessary incarceration; false negatives potentially exposing the public to unacceptable levels of risk. Risk assessment is therefore a complex and high stakes task for psychologists.

\section{Research into risk assessment process}

Little empirical work has focused on processes involved in psychological risk assessment in prisons (Elbogen, 2002) with research tending to focus on predictive accuracy (Weaver, 2014). Unstructured clinical judgement has tended to compare unfavourably against structured, mechanical approaches (Grove \& Meehl, 1996) and consequently, there has been an emphasis on developing structured risk assessment 
tools that minimise the role of clinical judgement. These include actuarial risk assessment instruments (ARAIs, e.g., the Violence Risk Appraisal Guide, Harris, Rice \& Quinsey, 1993) and structured professional judgement approaches (SPJs; e.g., Historical-Clinical-Risk Management-20, version 3 (HCR-20v3), Douglas, Hart, Webster \& Belfrage, 2013). SPJs and ARAIs have the additional advantage of appearing to make risk assessment objective and scientific (Yen \& Tafarodi, 2011). However in practice, clinical judgement is essential to the application of SPJs (and to a lesser extent, ARAIs). Psychologists must decide how to gather and analyse relevant information. They must decide on the strength and relevance of empirically derived risk factors. Information is usually obtained during an interview which requires considerable clinical skill (Logan, 2013; Shingler, Sonnenberg \& Needs, 2017). Therefore, whether or not an ARAI or an SPJ is used, the role of the psychologist remains central to the risk assessment process (Peckover et al., 2011). Developments in risk assessment tools have not removed the need for skilled clinicians to apply, interpret and report them (Gannon \& Ward, 2014; Hough, 2010) or for prisoners to engage with them.

\section{Psychologists in prisons}

Psychological risk assessment requires substantial contact between prisoner and psychologist. Therefore, reports of deteriorating relationships between prisoners and psychologists are concerning (Gannon \& Ward, 2014; Maruna, 2011; Shingler et al., 2017) as are reports of limited respect for psychological knowledge in prisons. For example, Maruna (2011) reported a tendency for prisoners to view psychologists as untrustworthy and hostile. Sparks (1998) found prisoners resented the power they felt psychologists had over release and progression decisions. Crawley (2004) suggested that prison officers had little respect for psychological expertise. It remains unclear how 
psychologists experience their relationships with prisoners and colleagues and how these relationships affect their risk assessment practice.

Prison-based psychologists appear to be more vulnerable to stress and burnout than psychologists working in other settings (Senter, Morgan, Serna-McDonald \& Bewley, 2010). Possible explanations for this include exposure to secondary stress (via accounts of serious offences, distress and violence), working with challenging and hostile clients and working in highly bureaucratic organisations (Gallavan \& Newman, 2013). Given the potential challenges psychologists experience in their professional relationships and the importance of psychological assessment to Parole Board decision making, it is possible that conducting risk assessment contributes to occupational stress.

\section{Current aims}

To summarise, there seem to be considerable demands on psychologists conducting risk assessments in prisons. Knowing more about psychologists' experiences could help psychologists to navigate these demands more effectively. This in turn could improve the service provided to prisoners, the Parole Board and the public. Consequently, the current research question was:

- What are qualified psychologists' experiences of conducting risk assessments with indeterminate sentenced prisoners?

\section{Design and method}

Data were collected using individual, semi-structured interviews with qualified prisonbased psychologists. Interview data were analysed using Grounded Theory methods (Glaser \& Strauss, 1967). Member checking exercises (Creswell \& Miller, 2000) were conducted with psychologists to support and develop the analysis.

\section{Participants and recruitment}


Approval for the study was obtained from the National Offender Management Service (NOMS) and the University of Portsmouth's Ethics Committee. Qualified psychologists, employed by Her Majesty's Prison Service (HMPS) were invited to volunteer for the study. Emails were sent to all Regional Psychologists (senior psychologists with overall responsibility for the provision and organisation of psychological services in a geographical region of England and Wales) requesting permission to contact their staff to invite them to participate. Some Regional Psychologists provided email addresses for all of their staff who were duly contacted. Some chose to gate keep the process and pass on the contact details of psychologists willing to participate. Interviews were arranged with the first people who volunteered and with whom a mutually convenient interview time could be identified. Interviews were conducted until data saturation was reached. In total, eleven psychologists participated in an interview between May and July 2015. Ten were women; ${ }^{2}$ participants' ages ranged from 33 to 48 years; all described their ethnicity as White British. Participants had worked within forensic psychology for between 8 and 29 years, and had been chartered for between 1 and 17 years. Six psychologists regularly conducted risk assessments; four regularly supervised risk assessments. One psychologist with experience of risk assessment was currently managing risk assessment provision.

\section{Procedure}

\footnotetext{
${ }^{2}$ Statistics about the gender composition of different functions of the NOMS workforce are not in the public domain but personal experience of working in and around the prison service for over twenty years suggests that the vast majority of prison based psychologists are women.
} 
Six interviews were conducted in person and five by telephone (due to geographical distance) using a pre-designed interview guide. Initial questions were exploratory to allow participants freedom to respond from their own perspectives. For example, the first question was: 'What I am most interested in is what it is like for you to conduct risk assessments with indeterminate sentenced prisoners - how you think and feel about it. Can you tell me a bit about your experiences?' Interviews were responsive to the contributions and experiences of participants.

Interviews lasted between 50 and 85 minutes. They were recorded using a digital voice recorder and transcribed by the interviewer. All identifying information was removed, and each participant was allocated a pseudonym. ${ }^{3}$

\section{Analysis}

Data were collected and analysed in line with Grounded Theory (GT) principles. In particular, analysis drew on Urquhart's (2013) approach as well as principles outlined by Glaser and Strauss (1967) and Charmaz (2006). In the first stage of analysis, line-byline coding was conducted to identify and label discrete units of meaning (open coding). The second stage of analysis (selective coding) involved grouping of open codes together into categories of meaning. It also involved searching for different representations of the same units of meaning within and between transcripts, at the same time as staying awake to the presence of new ideas. The final level of coding (theoretical coding) involved identifying broader categories that could encompass a range of open and selective codes and provide a meaningful understanding of psychologists' experiences.

\footnotetext{
${ }^{3}$ The identity of the single male participant was protected by the use of a number of genderneutral pseudonyms.
} 
Analysis was discussed and refined in peer debriefing sessions (Cresswell \& Miller, 2000; Urquhart, 2013) with the research team. In member checking exercises (Cresswell \& Miller, 2000), findings were discussed with a further eighteen qualified psychologists (fifteen women and three men), selected for convenience, in three group and two individual sessions. These sessions involved a presentation of key elements of the emerging analysis, and opportunity to question, challenge and affirm the results. Overall, the member checking exercises resulted in affirmation of key analytic categories and the provision of additional rich detail and examples. There were no areas of the analysis that provoked disagreement and to which participants could not relate.

\section{Results and discussion}

As illustrated in Figure 1, analysis identified 'The Challenging Context of Risk Assessment' as a major category of meaning. This had two main features: (1) pressure resulting from limited resources and (2) challenging environmental factors. The challenging context provided the backdrop for the other major category, 'Risk Assessment as a Weighty Task', which comprised three sub-categories, as illustrated.

\section{Insert Figure 1 here}

\section{The challenging context of risk assessment}

\section{Pressure of limited resources}

Psychologists' contributions suggested pressure resulting from conducting risk assessment in a climate of limited time and resources:

I think it's the, the time pressures in terms of doing, er lots of things going on, lack, lack of resources nationally really across the prison service. We're all trying to do much more work than fits into our hours. (Vicky) 
Participants described how resource pressures meant they were constantly 'firefighting' to meet Parole Board demands rather than providing assessments in a strategic and meaningful way from the outset. These experiences are consistent with the concept of moral distress in which organisational priorities conflict with professionals' ethical priorities and responsibilities, preventing professionals from taking action they believe to be morally right (Austin, Rankel \& Kagan, 2005; Epstein \& Hamric, 2009). Moral distress is often a symptom of deeper organisational problems and can arguably contribute to burnout (Epstein \& Hamric, 2009), something to which prison-based psychologists may already be vulnerable (Senter et al., 2010).

Psychologists described trying to keep time pressure out of the risk assessment interview, establishing the interview as a priority task (Shingler et al., 2017). However, tasks that required thought and reflection, such as report writing or supervision, seemed more vulnerable to resource pressure. Nolan and Walsh (2012) suggested that the crisisheavy prison environment could further interfere with reflective processes, potentially resulting in double jeopardy for psychologists.

Both psychologists and prisoners believed that a rushed assessment was more likely to be experienced as anti-collaborative and disrespectful (Shingler et al., 2017). Psychologists described the value of time:

[Having more time has] made a huge difference. I mean, er, even just having a whole session to dedicate to introductions, rapport building, consent, making sure that all of that is thoroughly understood, and making sure that the prisoner knows exactly what that experience is going to be like and building that relationship up. (Ava)

Pre-assessment meetings were popular amongst psychologists. They provided time and opportunity to discuss the assessment process and ensure consent was properly 
informed and not a 'paper exercise' (Karen). Psychologists believed this broke down barriers, built trust and helped prisoners feel valued as individuals (Shingler, et al., 2017). Pre-assessment meetings also provide opportunity to negotiating working relationships (Murakami, 2003). Whilst psychologists might be concerned about time implications, investment of time upfront could arguably save time in the long run, by virtue of greater cooperation from prisoners and reduced complaints (Shingler \& Mann, 2006).

\section{Pressure of the environment}

The second strand to the challenging context was pressure created by the physical and interpersonal environment. The negative impact of the prison environment on staff has been previously noted (Clarke, 2013; Crawley, 2004; Elliott \& Daley, 2013; Gerstein, Topp \& Correll, 1987; Schaufeli \& Peeters, 2000) and the findings here reflect this impact on psychologists.

Psychologists described prison as 'oppressive' and 'depressing'. Claire noted that she felt 'more vulnerable now in the, in the interview place' and that 'the wings don't feel as safe anymore'. She attributed this largely to budget cuts resulting in fewer prison officers on the wings.

Some psychologists experienced prison work as insular and 'shut off from the outside' (Karen). Psychologists lacked opportunities for collaboration with colleagues working in related services. There was a sense of psychologists feeling 'very isolated and very alone' (Karen) in their risk assessment practice rather than feeling part of a multi-disciplinary team. This isolation was reflected in participants' descriptions of their relationships with prison staff: Steph felt like a 'hindrance' to prison staff. Laura believed prison managers did not see psychologists making any useful contribution to the establishment. 
The challenging interpersonal nature of risk assessment was noted as another environmental pressure. Karen and Sam both felt that, as qualified psychologists, they tended to be allocated more complex assessments. This resulted in a 'lack of respite of kind of non-complicated work', with psychologists working on 'complicated case, after complicated case, after complicated case' (Charlie). Psychologists also described being stereotyped by prisoners as either 'psycho-babes, and all this sort of, the young, the young forensic psychologist' (Karen), or 'young unqualified people, to just sort of test out and have the prisoners as guinea pigs' (Lorna). There was a view amongst psychologists that prisoners viewed them with hostility and suspicion (Maruna, 2011; Warr, 2008). Gerstein et al. (1987) noted the consequences of 'negative, unrewarding, and draining' staff-prisoner interactions (p.362). Similarly, Schaufeli and Peeters (2000) reported that negative contact between correctional officers and prisoners was related to emotional exhaustion and depersonalisation. If psychologists, who are stressed as a result of their negative interactions with prisoners, protect themselves by depersonalising and distancing themselves from prisoners, this potentially reinforces prisoners' negative views of psychologists, thereby making punishing interactions more likely. A distant, impersonal style is also inconsistent with the interviewing approach that psychologists and prisoners agree is best practice - one which achieves a human connection between psychologist and prisoner (Shingler, et al., 2017).

Some contributions indicated that negative views of psychologists within prisons might be partly a consequence of changes to the organisation of psychological services. In some regions, instead of being based in specific prisons, psychologists worked in regional teams, visiting different prisons within the region to conduct specific tasks as the need arose. These changes to working practice were made as a way of managing a scarce resource. Consequently, in some geographical regions, psychologists 
were 'parachuted in' (Steph) to conduct risk assessments, rather than being part of the prison team. Laura felt this resulted in a lack of informal contact between psychologists, staff and prisoners, meaning fewer opportunities to challenge stereotypes and build positive working relationships. Research suggests that co-operative relationships with co-workers are important to psychologists working in prisons (Boothby \& Clements, 2002) and contribute towards job satisfaction. If working relationships are compromised, the intersubjective web of expectations, attitudes and experiences within prisons (Nolan \& Walsh, 2012) may contribute to psychologists feeling isolated and disregarded by colleagues and mistrusted by prisoners. Such perceptions, whether accurate or not, may affect psychologists' well-being and interfere with the process of conducting a risk assessment. Nolan and Walsh (2012) highlight the value of supervision in understanding complex relationships in prisons. Given the resource pressures described above, and the observation of a number of participants about the lack of clinical supervision for qualified staff, ${ }^{4}$ it is possible that such opportunities for reflection are limited for psychologists.

In summary, environmental pressures included managing challenging relationships, feeling isolated and unsafe, whilst working in an oppressive and depressing environment. However, there was also evidence of positive experiences of conducting assessments. Maria described risk assessment as involving 'creative tension' and a 'voyage of discovery'. Alex explained that working with prisoners 'face-to-face and try and understand their case is what's most interesting'. Other work has found a similar tension between enjoyment and stress in correctional psychological work

\footnotetext{
${ }^{4}$ There is no legal requirement for qualified psychologists to receive clinical supervision (British Psychological Society, 2017) but a number of psychologist participants indicated that it would be beneficial.
} 
(Clarke, 2013). Understanding more about psychologists' experiences of risk assessment enables identification both of stressors and areas of pride, enjoyment and job satisfaction.

\section{Risk assessment as a weighty task}

Risk assessment is conducted within the challenging context described above and psychologists experienced it as a weighty task. The weight derived both from a sense of responsibility and from the expectations of other professionals. The dilemma of developing competence in risk assessment amongst trainee psychologists added to the weightiness of the task for qualified psychologists. These categories of meaning are described in more detail below.

Weight of personal responsibility

Analysis indicated that psychologists experienced risk assessment as a 'massive responsibility' (Karen and Sam). The weight of responsibility was described as both immediate and future-related. The immediate responsibility lay in psychologists making recommendations that had significant consequences for prisoners, as if 'this is my, this is my life right now, erm, in your hands' (Laura). The responsibility of conducting the assessment, reaching recommendations, and giving oral evidence to the Parole Board was experienced by some psychologists as stressful and anxiety provoking.

The future-related responsibility lay in the nature of the interaction with the prisoner and the resulting implications for his attitude towards psychologists and other professionals. Karen described herself as a 'gatekeeper to other services' in that her involvement might determine how well a prisoner engaged with other criminal justice professionals. Several psychologists described the potentially enduring impact of a negative experience with a psychologist: Lorna noted 'one damaged experience, unfortunately in a prisoner's mind, because it was so damaging, can outweigh many 
positive experiences'. Proulx, Tardif, Lamoureax and Lussier (2000) noted the importance of clients being engaged in assessment in order to have a meaningful role in risk-management. The idea that a single negative experience of psychological assessment could compromise a prisoner's willingness to engage in risk-management (Warr, 2008) understandably adds to the pressure psychologists feel to get risk assessment right.

Psychologists reported having numerous responsibilities in risk assessment. They felt responsible to prisoners, the Parole Board and the public. Participants recognised tension in their responsibilities and commented on the challenges of meeting these varying needs (Austin, Kagan, Rankel \& Bergum, 2008). Steph was explicit about the weighty process of balancing these responsibilities (Shingler et al., 2017):

We do go in with that in our mind, that we're there to, erm, protect the public, which I suppose in a way takes a little bit of that neutrality away... but I think we have to balance that with the needs of the prisoner, erm and think, you know, erm about that, you know, that capacity to change and erm, you know, there's but I suppose it's a bit of a balancing act, it's really difficult.

There was keen awareness of the consequence of errors of judgement in risk assessment - namely fear of clients committing further offences:

I think erm, none of us want victims, do you know what I mean? I'm sure erm one of our main drivers is that we want to prevent people being future victims, and I think that, yeah, I think those sorts of thoughts are behind some of the ways that we behave in assessments. (Sam)

Here, Sam indicated how fear about reoffending could affect psychologists' approach to assessments. Stanford (2009) and McDermott (2014) discussed the implications for professionals working in a climate of fear, including fear of being 
blamed when things went wrong. Stanford argued that social workers were more vulnerable to 'defensive and morally conservative practices' (p. 1078) when they felt unsafe. Similarly, Adshead (2014) suggested that motivation to avoid blame for clients' recividism could act as a 'powerful inducement to detain longer' (p. 8). The sense of weight given to psychological assessment and the consequent fear of errors might partly explain why psychologists have been described as more risk averse than other professionals (Forde, 2014). This idea was supported by some participants in this study: Usually that the psychologist is saying "no they're too risky" and other people are saying it's OK for them to move on. So I think it's probably not, probably less usual for it to happen the other way. (Laura)

We cannot draw any conclusions about the extent to which psychologists make overly cautious recommendations in order to contain their anxiety. The ethical and practice implications here need further reflection and exploration.

Unsurprisingly, psychologists described using specific coping strategies to manage the weight of responsibility. First, participants reminded themselves of the limitations of their role in risk assessment:

It's not us that are making the decision. We are providing an opinion to the Parole Board which they may or may not agree with, but they are ultimately making that decision. (Ava)

The reminder that 'it's the Parole Board's decision' (Karen) helped some psychologists manage the burden of responsibility. It facilitated a sense of teamwork, reduced isolation and enabled psychologists to feel 'part of a bigger picture' (Ava).

Second, reminders of the limitations of risk assessment itself were helpful:

Risk assessment is not an absolute science is it? It's not a science and we get it wrong. (Steph) 
This frank recognition was welcomed by Parole Board members (Shingler, 2017); it is also consistent with ethical risk assessment (Vess et al., 2017).

Finally, psychologists talked about managing responsibility via maintaining professional standards, including discussing the assessment with other professionals involved with the client and seeking peer consultation or supervision. Supervision and peer support can ameliorate work-related stress in correctional workers, especially women (Lindquist \& Whitehead, 1986; Van Voorhis, Cullen, Link, \& Wolfe, 1991) and Nolan and Walsh (2012) emphasised the value of supervision when working in complex interpersonal settings.

\section{Weight of expectation}

Psychologists reported a weight of expectation from others. A number of psychologists described the emphasis given to their risk assessments in Parole Board decisions:

You have to be mindful that, you know, for them there is no, there's no fixed date when they're getting out... and a lot rides on the psychologist's assessment; erm, so I think, erm you just, you have to be er, kind of empathic about that really and just recognise that for them this could cause a lot of fear because, you know, if, if the psychologist is saying something that is really negative, it can, it can change the course of the parole outcome. (Alex)

Alex's summary of psychologists' power is consistent with other investigations into prisoners' experiences of prison life (Crewe, 2011; Crewe, 2012; Shingler et al., 2017; Warr, 2008). Additionally, psychologists' views of the weight placed on psychological opinion by the Parole Board are consistent with Parole Board members' perspectives (Shingler, 2017; Shingler \& Needs, 2018a). 
Participants highlighted broader reliance on psychological risk assessment: psychologists reported that sometimes Offender Managers and Offender Supervisors ${ }^{5}$ 'won't make an opinion of their own until they've seen ours' (Charlie) and they wanted the psychologist's report in order to finalise their own assessment:

My deadline is four weeks before everyone else's to give them time to, to read yours, decide what they think. Erm, and I think that can be helpful, but it can make you feel very isolated and very alone and feel like there's a lot of responsibility on your shoulders. (Karen)

Karen's comment encapsulates the sense of weight and responsibility and the personal impact of this. Others described the reliance on psychological opinion as 'scary', 'stressful' (Charlie) and 'overwhelming' (Alex). Laura explained that sometimes stakeholders would 'expect your [report] is suddenly going to explain everything'. This reflects a pressure to know the answers and to provide clear-cut recommendations when, in reality, psychologists often have to deal with chronic uncertainty. This is especially true when working with complex clients 'where a path forward erm is, can at times be almost impossible to identify' (Lorna). The weight given to psychological opinion in these complex decisions contributed to the experience of risk assessment as a 'massive responsibility' as discussed above. McDermott (2014) described the challenges for healthcare professionals in "determining the "right" interventions for individual patients amid the "swirl of data" surrounding them' ( $p$.

\footnotetext{
${ }^{5}$ Offender Managers are community-based probation officers who manage a client's sentence once s/he is released from custody. Offender Supervisors are prison-based, and can be probation officers or specially trained prison officers who manage the progression of a client's sentence whilst in custody.
} 
183). Austin et al. (2008) suggested that the weight of others' expectations contributed to psychiatrists' experience of moral distress. They similarly noted uncertainty in psychiatry when making life-changing decisions, 'in psychiatry we know we're limited' (p. 92, italics in original). Some participants discussed how a range of opinions in risk assessment could make risk assessment more thorough and balanced. A relational responsibility approach to risk assessment (Austin et al., 2008, p. 96), in which different professionals with different training, experience and priorities come together to provide their perspectives on a problem may well be advantageous.

\section{The trainee dilemma}

Many psychological risk assessments are completed by Forensic Psychologists in Training (FPiTs). Analysis suggested that being assessed by an FPiT presented difficulties for some ISPs who 'you know, refuse to be seen by a trainee, they want qualified' (Charlie). Several psychologists empathised with this viewpoint:

I think some just genuinely don't think that a trainee would be competent enough. The word "trainee" kind of indicates, a bit like, would you go and have a trainee hairdresser? Does kind of instantly make you think, "ooh would they do it right?" (Claire)

Claire's comment suggests that the word "trainee" itself might cause ISPs to question the competence of FPiTs; this is noteworthy as many FPiTs remain trainees for several years whilst working towards qualification and may well have substantial experience in conducting risk assessments.

A solution to the reluctance of ISPs to be assessed by FPiTs might be for qualified psychologists to conduct risk assessments for ISPs. However, participants noted that this would remove opportunity for FPiTs to develop competence in risk assessment. This highlights a challenging dilemma. On one hand, allowing FPiTs to 
conduct high stakes risk assessments means risking errors that could put the public at risk and damage working relationships with prisoners - which in itself could have longterm risk-management implications (Proulx et al., 2000). After all, 'it's not like they're doing a trial run' (Charlie). On the other hand, 'it's difficult to train somebody properly in risk assessments without them, without them doing them' (Charlie). ${ }^{6}$ The current solution to this dilemma is for qualified psychologists to oversee and take clinical responsibility for FPiTs' work, raising additional issues for supervisors:

I think there's an added challenge of allowing someone to develop their voice as a practitioner; allowing them to make decisions, but particularly in the world of psychology, you know, also balancing that with the fact that I am accountable. (Lorna)

The balance of developing FPiTs as competent and autonomous practitioners at the same time as being ultimately accountable for their risk assessments added another element of weight to the already significant burden of responsibility.

The final strand to the trainee dilemma was qualified psychologists' unfavourable comparisons of their current risk assessment practice with their approach when they were in training. Ava described how inexperience added to environmental and interpersonal challenges, exacerbating the stress of risk assessment. Participants suggested that FPiTs were particularly vulnerable to errors in interpersonal skills that facilitated rapport building and collaboration:

${ }^{6}$ This dilemma was also noted by one of the prisoner participants in another strand of this study (see Shingler, et al., 2017 for details) who said 'They are training but they have to learn in the real world setting. A chef doesn't stay at home and cook in the kitchen he goes into er, a restaurant kitchen to train in the field, so it's got to be done'. 
I think when you start, you know, we, we sort of drum into ourselves and into, into other people the importance about, you know, erm, competence, about confidentiality, about professionalism and boundaries, erm to the point where I think, you know people go in, go into an interview and think right, I must be very professional, I must have this and that, and can over-s, overlook sometimes the fact that you know, you're just a person, you're dealing with a person. (Alex) Alex believed that lack of experience could result in interview behaviour that was distant and lacking in humanity, both of which have been found to be counterproductive (Shingler et al., 2017). Similarly, a number of psychologists described how FPiTs were more vulnerable to rigidity, tending to stick to the script rather having 'some kind of free-flowing conversation where you're eliciting information' (Claire). Sookermany (2012) argued that following rules is a feature of novice performance and it is therefore unsurprising that this is observed amongst FPiTs. Alex described how experience and confidence enabled her to communicate more naturally during interviews:

So I think you move from a point where you have perhaps quite a fixed interview schedule, thinking I need to hit these points, to, erm, a position where you go into the interview and can just say, you know, "So why are we here? Tell me about yourself, tell me about your life. How did you get to be in this position?"

It is possible that being assessed by FPiTs, especially those who lack experience and confidence to have fluid but professional boundaries, a naturally conversational yet assertively focused style and make a human connection (Shingler et al., 2017) could unwittingly contribute to the troubled relationships between psychologists and prisoners identified in this study and reported elsewhere (Gannon \& Ward, 2014; Maruna, 2011). 
Finding the balance of 'having natural conversation which nevertheless ticks all those points on your list' (Alex) is arguably a priority of risk assessment training (Shingler et al., 2017).

\section{Conclusions and implications}

Psychologists conducting, supervising and managing risk assessments work in a challenging context, characterised by resource pressure and stressful environmental and interpersonal features. This environmental pressure exacerbates qualified psychologists' sense of personal responsibility and the experienced weight of others' expectations. The dilemma of developing FPiTs' competence in risk assessment whilst remaining accountable for their work adds to the weightiness of the task.

This was a small scale study which provided a rich understanding of the experiences of the participants. Each participant, whether interviewed in person or by telephone provided an insightful and reflective account of their experiences and perspectives. Psychologists seemed to be glad to have an opportunity to reflect on their practice and on the broader issues associated with risk assessment.

There are, however, some limitations to the findings. Firstly, all the participants were volunteers; this may have affected the range of perspectives available and it is possible that random selection from the entire sample of qualified prison-based psychologists would reveal different perspectives. Secondly, whilst the qualified psychologists had a lot to say about the issues for FPiTs, this study did not directly explore the FPiTs' perspectives. A specific investigation into the experiences of FPiTs working in prisons conducting risk assessments would be a valuable next step.

An aim of this study was to use the understanding gained to facilitate improvements to practice. The results suggest the following options for maintaining and improving standards in psychological risk assessment: 
- Prioritise supervision for qualified psychologists. This could ameliorate stress associated with risk assessment, as well as supporting psychologists in their role as supervisors for FPiTs. It could help psychologists to navigate the complexities of professional relationships in prisons through reflexive engagement on an intersubjective process (Nolan \& Walsh, 2012; Shingler \& Needs, 2018b).

- Reflect on the limits of psychological risk assessment and delineate these in reports. This could help psychologists manage the weightiness of the task and is consistent with Parole Board members' preferences (Shingler, 2017).

- Continue to integrate psychologists into their workplaces to improve working relationships with both prisoners and prison-based colleagues.

- Encourage pre-assessment meetings with prisoners as a means of providing additional opportunities for building rapport as well as beginning to overcome barriers of suspicion and hostility.

- Focus on effective interpersonal approaches to risk assessment interviewing early on in the training and development of FPiTs.

- Facilitate greater collaboration with colleagues in related settings. This could provide opportunities to share good practice approaches to risk assessment as well as provide opportunities for personal and professional development. This could protect against stress and burnout by providing a greater sense of competence and job satisfaction.

- Promote relational responsibility in risk assessment, in which different professionals contribute on equal terms and within equal timeframes. This could result in more comprehensive assessment of prisoners which, in turn, could 
alleviate the burden on psychologists as well as providing a better service to prisoners, the Parole Board and the public.

In summary, this study of qualified, prison-based psychologists' risk assessment practice provides insight into the experiences of this under-researched group. It can facilitate improvements to practice as well as enabling psychologists to build on areas of strength.

\section{Acknowledgements}

The authors would like to thank Dr. Paul Morris and Dr. Jo Bailey for their comments on earlier drafts of this paper.

\section{Disclosure statement}

In accordance with Taylor \& Francis policy and my ethical obligation as a researcher, I am reporting that, whilst this research was conducted as part of my $\mathrm{PhD}$ studies at the University of Portsmouth, I also work on a consultancy basis for Her Majesty’s Prison and Probation Service (HMPPS). I did not receive any financial support from HMPPS in relation to this research and the analysis was conducted with no involvement of HMPPS colleagues. 


\section{References}

Adshead, G. (2014). Three faces of justice: Competing ethical paradigms in forensic psychiatry. Legal and Criminological Psychology, 19(1), 1-12.

Austin, W., Kagan, L., Rankel, M. \& Bergum., V. (2008). The balancing act: Psychiatrists' experience of moral distress. Medical Health Care and Philosophy, 11, 89-97.

Austin, W., Rankel, M. \& Kagan, L. (2005). To stay or to go, to speak or to stay silent, to act or not to act: Moral distress as experienced by psychologists. Ethics and Behaviour 15(3), 197-212.

Boothby, J. L., \& Clements, C. B. (2002). Job satisfaction of correctional psychologists: Implications for recruitment and retention. Professional Psychology: Research and Practice, 33(3), 310.

Bowers, L. \& Friendship, C. (2017). Forensic Psychological Risk Assessment for the Parole Board. In K. Browne, A. R. Beech, L. A. Craig \& S. Chou (Eds). Assessments in forensic practice: A handbook (pp103-121). Chichester UK: John Wiley \& Sons, Ltd.

Charmaz, K. (2006). Constructing grounded theory: A practical guide through qualitative analysis. London, UK: Sage.

Clarke, J. (2013). The resilient practitioner. In J. Clarke \& P. Wilson (Eds). Forensic psychology in practice: A practitioner's handbook (pp. 220-219). Basingstoke, UK: Palgrave MacMillan

Crawley, E. (2004). Doing prison work: the public and private lives of prison officers. Cullumpton, Devon, UK: Willan Publishing. 
Creswell, J. W., \& Miller, D. L. (2000). Determining validity in qualitative inquiry. Theory into practice, 39(3), 124-130.

Crewe, B (2011). Soft power in prison: Implications for staff-prisoner relationships, liberty and legitimacy. European Journal of Criminology, 8(6), 455-468.

Crewe, B. (2012). The prisoner society: Power, adaptation and social life in an English prison (Clarendon Studies in Criminology) Oxford: Oxford University Press.

Douglas, K. S., Hart, S. D., Webster, C. D., \& Belfrage, H. (2013). HCR-20 (Version 3): Assessing risk for violence. Burnaby, BC, Canada: Mental Health, Law and Policy Institute, Simon Fraser University.

Elbogen, E. B. (2002). The process of violence risk assessment: A review of descriptive research. Aggression and Violent Behaviour, 7, 591-604.

Elliott, K. A., \& Daley, D. (2013). Stress, coping, and psychological well-being among forensic health care professionals. Legal \& Criminological Psychology, 18(2), 187-204.

Epstein, E. G. and Hamric, A. B. (2009). Moral distress, moral residue and the crescendo effect. Journal of Clinical Ethics, 20(4), 330-342.

Forde, R. A. (2014). Risk assessment in parole decisions: A study of life sentence prisoners in England and Wales. Foren. Psy. D. thesis, University of Birmingham. Available from http://etheses.bham.ac.uk

Gallavan, D. B. \& Newman, J. L. (2013). Predictors of burnout among correctional mental health professionals. Psychological Services 10(1), 115-122.

Gannon, T. A. and Ward, T. (2014). Where has all the psychology gone? A critical review of evidence-based psychological practice in correctional settings. Aggression and Violent Behaviour, 19, 435-446. 
Gerstein, L. H., Topp, C. G. \& Correll, G. (1987). The role of the environment and person when predicting burnout among correctional personnel. Criminal Justice and Behaviour, 14(3), 352-369.

Glaser, B. G., \& Strauss, A. L. (1967). The discovery of grounded theory: Strategies for qualitative research. New Brunswick, NJ: AldineTransaction.

Grove, W. M., \& Meehl, P. E. (1996). Comparative efficiency of informal (subjective, impressionistic) and formal (mechanical, algorithmic) prediction procedures: The clinical-statistical controversy. Psychology, Public Policy and Law, 2, 293323.

Harris, G. T., Rice, M. E., \& Quinsey, V. L. (1993). Violent recidivism of mentally disordered offenders: The development of a statistical prediction instrument. Criminal Justice and Behavior, 20, 315-335.

Hough, M. (2010). Gold standard or fool's gold: The pursuit of certainty in experimental criminology. Criminology and Criminal Justice, 10(1), 11- 22.

Kebbell, M. (2016, April). Policing sex crime intelligently: An intelligence-led approach. Keynote presentation at the Division of Forensic Psychology Annual Conference, Brighton, U.K.

Lindquist, C. A., \& Whitehead, J. T. (1986). Burnout, job stress, and job satisfaction among southern correctional officers: Perceptions and causal factors. Journal of Offender Counseling, Services, and Rehabilitation, 10, 5-26.

Logan, C. (2013) Risk assessment: Specialist interviewing skills for forensic practitioners. In C. Logan \& L. Johnstone (Eds), Managing clinical risk: A guide to effective practice (pp. 259-292). Oxford: Routledge. 
Maruna, S. (2011). Why do they hate us? Making peace between prisoners and psychology. International Journal of Offender Therapy and Comparative Criminology 55(56), 671-675.

McDermott, F. (2014). Complexity theory, trans-disciplinary working and reflective practice. In A. Pycroft \& C. Bartollas (Eds.), Applying complexity theory: Whole systems approaches to criminal justice and social work, (pp. 181-198). Bristol, UK: Policy Press.

Murakami, K. (2003). Orientation to the setting: Discursively accomplished intersubjectivity. Culture \& Psychology, 9(3), 233-248.

Nolan, G. \& Walsh, E. (2012). Caring in prison: The intersubjective web of professional relationships. Journal of Forensic Nursing 8, 163-169.

Parole Board (2018). Parole Board information on Indeterminate Sentence Prisoners (ISPs). Retrieved from https://www.gov.uk/government/news/parole-boardinformation-on-indeterminate-sentence-prisoners-isps

Peckover, S., Broadhurst, K., White, S., Wastell, D., Hall, C. and Pithouse, A. (2011). The fallacy of formalisation: Practice makes process in the assessment of risks to children. In H. Kemshall, and B. Wilkinson (Eds). Good practice in assessing risk: Current knowledge, issues and approaches (pp. 84-101). London: Jessica Kingsley

Proulx, J., Tardif, M.., Lamoureux, B., \& Lussier, P. (2000). How does recidivism risk assessment predict survival? In D. R. Laws, S. M. Hudson, \& T. Ward, (Eds.), Remaking relapse prevention with sex offenders: A sourcebook, (pp. 466-484). Thousand Oaks, CA: Sage Publications. 
Schaufeli, W. B., \& Peeters, M. C. (2000). Job stress and burnout among correctional officers: A literature review. International Journal of Stress Management, 7(1), $19-48$.

Senter, A., Morgan, R. D., Serna-McDonald, C., \& Bewley, M. (2010). Correctional psychologist burnout, job satisfaction, and life satisfaction. Psychological Services, 7(3), 190-201.

Shingler, J. (2017). Psychologists' role in Parole Board decision making: What do Parole Board members think about psychological assessment? Forensic Update, 126, 2227.

Shingler, J., \& Mann, R. E. (2006). Collaboration in clinical work with sexual offenders: treatment and risk assessment. In W. L. Marshall, Y. M. L. Fernandez, L. E. Marshall, \& G. A. Serran, (Eds). Sexual Offender Treatment: Controversial Issues (pp225-239). Chichester, UK: Wiley.

Shingler, J., \& Needs, A. (2018a). The role of psychological risk assessment in Parole Board decision making: An exploration of the perspectives of psychologists, indeterminate sentenced prisoners and Parole Board members. Prison Service Journal, 237, 36-40.

Shingler, J., \& Needs, A. (2018b). Contextual influences in prison-based psychological risk assessment: Problems and solutions. In G. Akerman, A. Needs \& C. Bainbridge (Eds). Transforming environments and rehabilitation: A guide for practitioners in forensic settings and criminal justice, (pp. 323-347). Abingdon, UK: Routledge.

Shingler, J., Sonnenberg, S. J., \& Needs, A. (2017). Risk assessment interviews: Exploring the perspectives of psychologists and indeterminate sentenced 
prisoners in the United Kingdom. International Journal of Offender Therapy and Comparative Criminology, 62(10), 3201-3224.

Sookermany, A. M. (2012). What is a skillful soldier? An epistemological foundation for understanding military skill acquisition in (post) modernized armed forces. Armed Forces \& Society, 38(4), 582-603.

Sparks, C. (1998). Lifers' views of the lifer system: Policy versus practice. Prison Reform Trust.

Stanford, S. (2009). 'Speaking back' to fear: Responding to the moral dilemmas of risk in social work practice. British Journal of Social Work, 40(4), 1065-1080.

Urquhart, C. (2013). Grounded theory for qualitative research: A practical guide. London, UK: Sage.

Van Voorhis, P., Cullen, F. T., Link, B. G., \& Wolfe, N. T. (1991). The impact of race and gender on correctional officers' orientation to the integrated environment. Journal of Research in Crime and Delinquency, 28, 472-500.

Vess, J., Ward, T. and Yates, P. ( 2017). The ethics of risk assessment. In K. Browne, A. R. Beech, L. A. Craig \& S. Chou (Eds). Assessments in forensic practice: A handbook (pp. 370-386). Chichester UK: John Wiley \& Sons, Ltd.

Warr, J. (2008). Personal reflections on prison staff. In Bennett, J., Crewe, B. and Wahidin, A. (Eds). Understanding prison staff. Willan Publishing, Cullumpton, Devon, UK.

Weaver, Beth. (2014). Control or change? Developing dialogues between desistance research and public protection practices. Probation Journal, 61(1), 8-26.

Webster, C. D., Douglas, K. S., Eaves, D., \& Hart, S. D. (1997). HCR-20: Assessing risk for violence (Version 2). Burnaby, BC, Canada: Mental Health, Law and Policy Institute. 
Yen, J. and Tafarodi, R. W. (2011). Becoming scientific: Objectivity, identity and relevance as experienced by graduate students in psychology. Forum:

Qualitative Social Research, 12(2). Retrieved from http://www.qualitativeresearch.net/. doi: 10.17169/fqs-12.2.1596 
Figure 1: Psychologists' experiences of conducting risk assessments with indeterminate sentenced prisoners

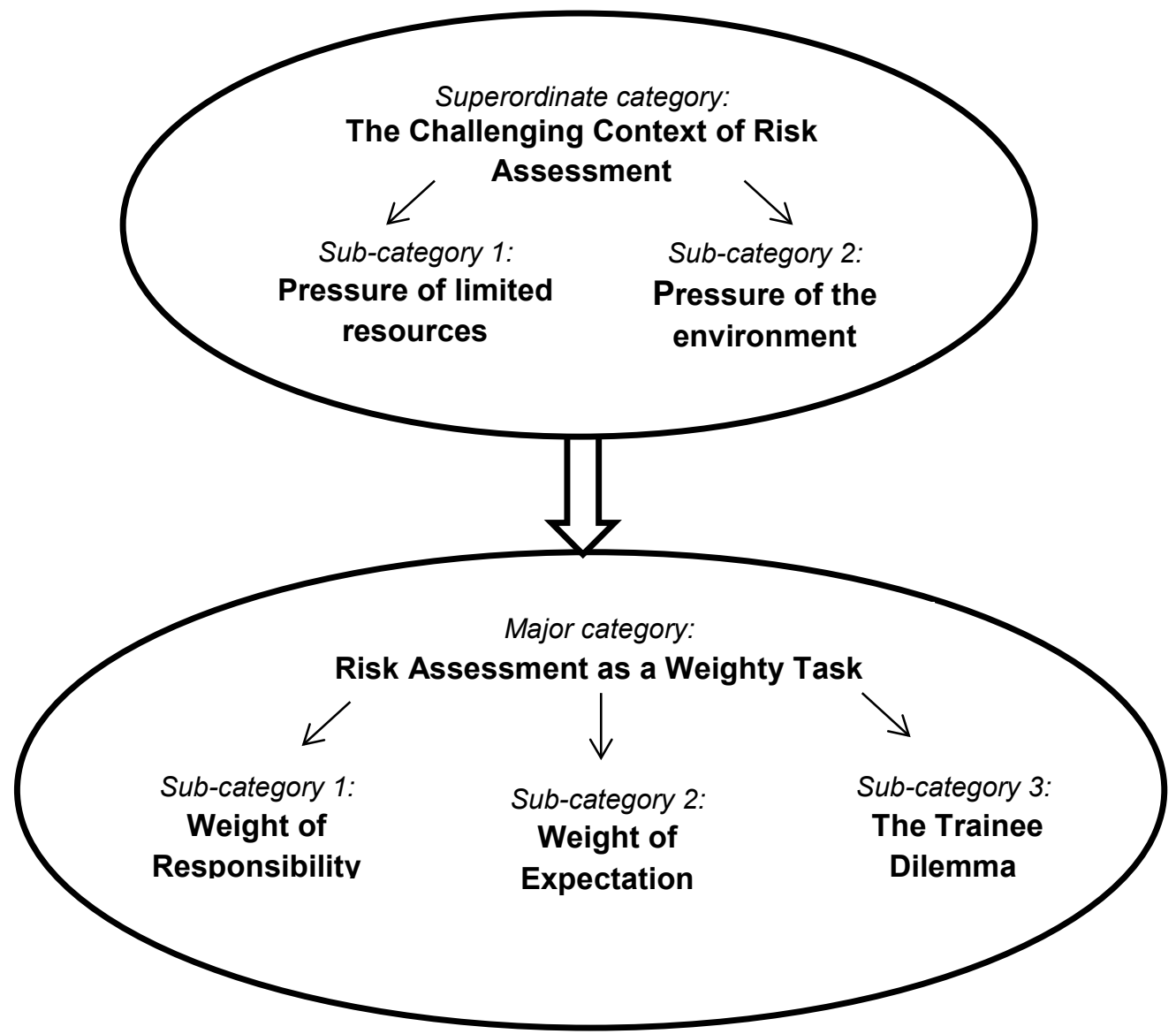

